\title{
Fixed-bed column study for the adsorptive removal of acid fuchsin using carbon-alumina composite pellet
}

\author{
M. Dutta $\cdot$ J. K. Basu
}

Received: 10 October 2011/Revised: 19 April 2012/ Accepted: 26 November 2012/Published online: 27 November 2013

(C) Islamic Azad University (IAU) 2013

\begin{abstract}
The carbon-alumina composite pellet was developed for the adsorption of acid fuchsin from its aqueous solution. The composite pellet was characterized using Brunauer-Emmett-Teller method, scanning Electron Microscopy and Fourier Transform Infrared Spectroscopy. The adsorption capacity of commercial alumina, commercial activated carbon and the prepared composite pellet was investigated against acid fuchsin, and the adsorption capacity was found to be increased in the order of alumina $<$ carbon-alumina composite pellet $<$ activated carbon. Although the adsorption capacity of carbon-alumina composite pellets was less than that of activated carbon, the use of the pelletized form of the present adsorbent was proven to be advantageous for the use in the packed-bed column. The experimental data were fitted to Langmuir, Freundlich and Temkin adsorption isotherms, and the equilibrium behavior was well explained by Langmuir isotherm. Besides, the kinetic behavior was well predicted by pseudo-second-order kinetics. The effects of inlet dye concentration $(10-20 \mathrm{mg} / \mathrm{L})$, feed flowrate $(5-15 \mathrm{~mL} / \mathrm{min})$ and bed height $(2.54-7.62 \mathrm{~cm})$ on the breakthrough characteristics were investigated using a fixed-bed column. The maximum removal capacity in the column study was found to be $343.87 \mathrm{mg} / \mathrm{L}$ with an initial dye concentration and flowrate of 20 and $10 \mathrm{~mL} / \mathrm{min}$ according to Bohart-Adams model. The breakthrough behavior was also effectively described by the Yoon-Nelson and Clark models.
\end{abstract}

M. Dutta · J. K. Basu $(\bowtie)$

Department of Chemical Engineering, Indian Institute of

Technology, Kharagpur 721302, West Bengal, India

e-mail: jkbosu@gmail.com
Keywords Acid fuchsin - Bohart-Adams model . Carbon-alumina pellet · Clark model · Column study . Equilibrium study $\cdot$ Yoon-Nelson model

\section{Introduction}

Dye is a major pollutant exuded by many industries all over the world, especially textile, paper, printing, leather, food, cosmetics, etc., which extensively use dyes to color their final product. Among the Asian countries, more than 800 dye manufacturing units are situated in India, which inevitably produce huge amount of colored waste water everyday (Verma 2008). Most of theses dyes are reported to be carcinogenic in nature and may be problematic if broken down anaerobically in the sediment, leading to the production of toxic amines. The presence of dyes in water reduces light penetration, and it has a derogatory effect on photosynthesis (Oguza and Keskinler 2005). The hematological process of some biota also affects when watercontaining colored substances enter into their system (Afaq and Rana 2009). Various types of toxic dyes such as acid dyes, basic dyes, reactive dyes and azo dyes are found in the inland surface water, originating from their different manufacturing sources and users. Among all these dyes, acid dye is most widely used in various industries and has a complex aromatic structure (Attia et al. 2006). Acid fuchsin is one of such dyes, which acts as an inhibitor of reverse transpose of immunodeficiency virus (Baba et al. 1998), as a copper corrosion inhibitor (Bastidas et al. 2003), in the preparation of organic-inorganic hybrid nano-composite (Hussein et al. 2004) and as a laboratory reagent. Various conventional methods are applied for the removal of dyes from waste water, but adsorption is worth mentioning among all. The activated carbon is one of the versatile 
adsorbents because of its large surface area and highly porous structure, but its high cost limits its widespread use. Besides, the use of powdered form of adsorbent has the great disadvantage of separation after being used. To overcome this difficulty, the carbon may be used in its pelletized form. In addition to carbon, alumina could be used as a good adsorbent for acid dyes (Gupta and Suhas 2009; Adak et al. 2005). Therefore, the use of carbonalumina composite pellet could be a better alternative for the removal of an acidic dye from their aqueous solutions (Balint and Miyazaki 2009).

The alumina has high mechanical properties and strong resistivity to thermal degradation (Massoud et al. 2004; Mahmoud et al. 2009). It also exhibits a high affinity to anionic dyes under basic condition and vice versa (Mahmoud et al. 2010). However, a few studies have focused on the removal of acidic dyes using polyurethane/chitosan composite ( $\mathrm{Zhu}$ et al. 2010), $\mathrm{MnFe}_{2} \mathrm{O}_{4} /$ bentonite nanocomposite (Hashemian 2010), $\mathrm{CuFe}_{2} \mathrm{O}_{4} / \mathrm{AC}$ composite (Zhang et al. 2007), $\mathrm{Fe}_{2} \mathrm{O}_{4} / \mathrm{AC}$ composite (Yang et al. 2008), but no approach has not made for the removal of acid fuchsin using carbon-alumina composite in the packed-bed column. Therefore, in the present investigation, a composite material was developed from commercial carbon and alumina using polyvinyl alcohol as a binder. The adsorption characteristics were investigated through batch and column study. The effects of different process parameters such as dye flowrate, bed height and inlet dye concentration on the breakthrough pattern were investigated in a fixed-bed adsorber. The adsorption breakthrough behavior was analyzed using Yoon-Nelson, Clark and Bohart-Adams models.

The whole research work had been carried out in Indian Institute Technology, Kharagpur, in the month of August and September.

\section{Materials and methods}

\section{Reagents}

Commercial granular activated carbon was supplied by SD Fine Chem. Ltd (Mumbai, India). The alumina powder for the present work was procured from Merck Specialities Pvt. Ltd (Mumbai, India). Acid fuchsin and polyvinyl alcohol (PVA) were purchased from Loba Chemie Pvt. Ltd (Mumbai, India).

Preparation of the adsorbent

The activated carbon (AC), alumina powder (Al) and PVA as a binder were mixed together in a weight proportion of $2: 2: 1$. Then, a small quantity of water was added to the mixture in order to prepare slurry, which was then heated up to $80^{\circ} \mathrm{C}$ for $4 \mathrm{~h}$ in a constant temperature water bath. The heating process was carried out till a sticky mass was formed, and then, the mass was shaped into spherical pellets.

The pellets were kept overnight in an air oven at $90{ }^{\circ} \mathrm{C}$ and placed in tubular furnace where they were heated up to $300{ }^{\circ} \mathrm{C}$ for $2 \mathrm{~h}$ in a flow of nitrogen gas $(300 \mathrm{~mL} / \mathrm{min})$. Next the activation was accomplished by continuing the heating for $1 \mathrm{~h}$. The resulting pellets were then cooled down to room temperature and stored in desiccator over silica gel. The prepared pellets were designated as carbonalumina composite (CAC) pellets. The surface properties of the composite materials were analyzed using BET apparatus (Autosorb-1, Quantachrome, USA). The surface morphology was investigated using scanning electron microscope (SEM) (Hitachi model SU-70) image, and the surface functional groups were determined using Fourier transform infrared spectroscopy (FTIR) (Spectrum-100, PerkinElmer, USA).

\section{Preparation of dye solution}

Acid fuchsin dye of commercial purity was used without further purification. The dye stock solution of concentration of $1000 \mathrm{mg} / \mathrm{L}$ was prepared by dissolving desired quantity of dye in distilled water. The experimental solutions of different initial concentrations were obtained by diluting the dye stock solution.

\section{Equilibrium and kinetic study}

Adsorption studies were performed by taking $100 \mathrm{~mL}$ of acid fuchsin solutions of varying initial concentration $(25-175 \mathrm{mg} / \mathrm{L})$ in a set of $250-\mathrm{mL}$ conical flasks containing $0.1 \mathrm{~g}$ adsorbents. The flasks were agitated in an isothermal mechanical shaker at $35{ }^{\circ} \mathrm{C}$ for $24 \mathrm{~h}$ to reach equilibrium, whereas the samples were withdrawn at various intervals of time using micropipette for kinetic study and centrifuged for $10 \mathrm{~min}$ to separate the adsorbent particles. The corresponding concentrations of acid fuchsin were analyzed in a double-beam UV-Vis spectrophotometer (Spectra scan UV 2600, Chemito, India).

\section{Adsorption column study}

A glass column of $1.2 \mathrm{~cm}$ i.d. and $12.5 \mathrm{~cm}$ length was used for the column study. The column was packed with CAC pellets followed by a layer of glass beads on both the sides to provide uniform flow of solution. To avoid entrapping of air bubbles inside the CAC pellets, the particles were soaked in appropriate amount of water and agitated until no air bubbles were detected in the solution. Dye solution of 
three different concentrations (10, 15 and $20 \mathrm{mg} / \mathrm{L}$ ) was percolated downward through the varying bed height $(25.4-76.2 \mathrm{~mm})$ at a desired flowrate of 5,10 and $15 \mathrm{~mL} / \mathrm{min}$. The samples were collected at various intervals of time and analyzed using an UV-Vis spectrophotometer.

\section{Results and discussion}

The comparison of adsorption capacity of CAC pellets with $\mathrm{AC}$ and $\mathrm{Al}$

The adsorption capacity of the prepared adsorbent was compared with pure alumina and commercial activated carbon (Fig. 1), and the adsorption capacity was found to be decreased in the following order.

\section{$\mathrm{Al}<\mathrm{CAC}$ pellet $<\mathrm{AC}$}

The maximum adsorption capacity of various adsorbents was determined at the equilibrium by plotting the equilibrium dye concentration $\left(\mathrm{C}_{\mathrm{e}}, \mathrm{mg} / \mathrm{L}\right)$ against the amount adsorbed $\left(\mathrm{q}_{\mathrm{e}, \mathrm{mg} / \mathrm{g}}\right)$. Although the adsorption capacity of CAC pellets was less than that of AC, the use of the pelletized form of the present adsorbent was proven to be advantageous for the use in the packed-bed column.

\section{Characterization of the prepared CAC pellets}

The surface area, total pore volume, micropore volume and average pore size of CAC pellets were determined by BET surface area analyzer.

The values of surface area, total pore volume and average pore size of CAC pellet were found to be $294.1 \mathrm{~m}^{2} / \mathrm{g}, 0.2643 \mathrm{cc} / \mathrm{g}$ and $35.95 \AA$. The surface morphology of CAC pellets was determined using SEM image.

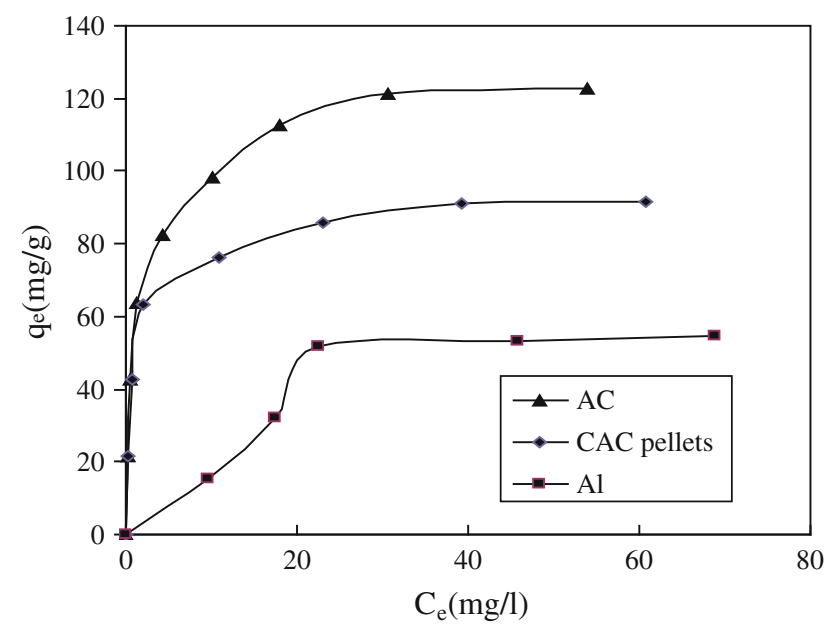

Fig. 1 Comparison of adsorption capacity of CAC pellets with pure alumina and commercial activated
As shown in Fig. 2, Al particles are uniformly dispersed on the surface of CAC.

The FTIR spectra of CAC pellets is shown in Fig. 3. The presence of various surface functional groups such as amine and alkene was detected at 1,019 and $1,020 \mathrm{~cm}^{-1}$ of FTIR spectra. Besides, the $\mathrm{C}-\mathrm{H}$ and $\mathrm{O}-\mathrm{H}$ bonds were detected at 1,422 and 3,350 $\mathrm{cm}^{-1}$, respectively (Kimberly and Saliba 1995).

\section{Kinetic study}

The adsorption kinetics data are shown by plotting instantaneous amount of adsorption $\left(\mathrm{q}_{\mathrm{t}}, \mathrm{mg} / \mathrm{g}\right)$ as a function of time (Fig. 4a, b). As shown in Fig. 4a, a quasi-state equilibrium is reached after $110 \mathrm{~min}$. The experimental data were fitted with pseudo-second-order kinetics at various initial dye concentrations as shown in Fig. 4b. In order to find out the controlling mechanism for the given

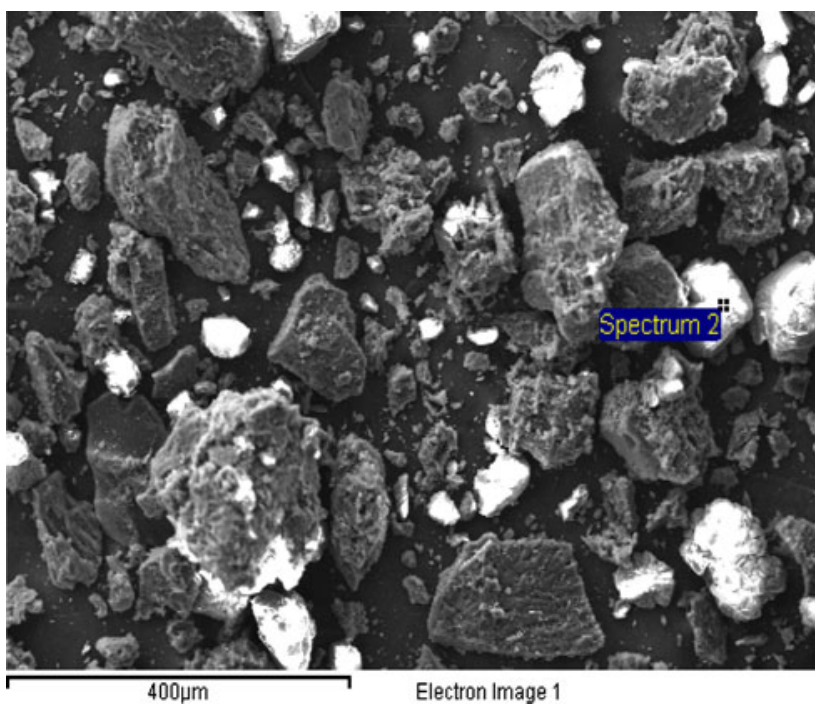

Fig. 2 SEM image of CAC pellet

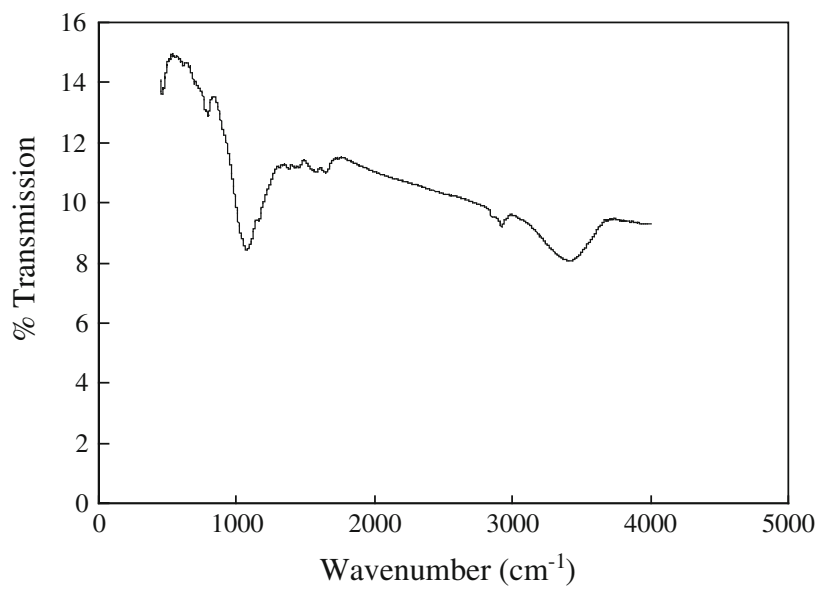

Fig. 3 FTIR spectra of CAC pellet 
Table 1 Adsorption kinetic constant, modeled by a pseudo-firstorder equation

\begin{tabular}{lllll}
\hline $\begin{array}{l}\text { Initial concentration } \\
(\mathrm{mg} / \mathrm{L})\end{array}$ & $\begin{array}{l}\mathrm{k}_{2} \\
(\mathrm{mg} / \mathrm{L})\end{array}$ & $\begin{array}{l}\mathrm{q}_{\mathrm{eq}, \text { exp }} \\
(\mathrm{g} / \mathrm{mg} \min )\end{array}$ & $\begin{array}{l}\mathrm{q}_{\mathrm{eq}, \text { calc }} \\
\left(\mathrm{mg} \mathrm{g}^{-1}\right)\end{array}$ & $\begin{array}{l}\mathrm{R}^{2} \\
\left(\mathrm{mg} \mathrm{g}^{-1}\right)\end{array}$ \\
\hline 50 & 0.0063 & 40.48 & 39.15 & 0.9974 \\
100 & 0.0014 & 71.13 & 75.19 & 0.9866 \\
150 & 0.0013 & 91.0 & 95.24 & 0.9910 \\
\hline
\end{tabular}

adsorption process, pseudo-first- and pseudo-second-order kinetic models were investigated.

The equation corresponding to the pseudo-first-order kinetic model is expressed as follows (Amin 2009):

$\log \left(q_{\mathrm{e}}-q_{\mathrm{t}}\right)=\log q_{\mathrm{e}}-\frac{k_{1}}{2.303} t$

where $q_{\mathrm{e}}$ and $q_{\mathrm{t}}$ refer to the amount of dye adsorbed (mg/g) at equilibrium and at any time, $t(\mathrm{~min})$, respectively, and $k_{1}$ is the equilibrium rate constant of the pseudo-first-order sorption $\left(\mathrm{min}^{-1}\right)$. Similarly, the pseudo-second-order kinetic model is given by Eq. 2 (Song et al. 2010):

$\frac{1}{q_{\mathrm{e}}-q_{\mathrm{t}}}=\frac{1}{q_{\mathrm{e}}}+k_{2} t$.

where $k_{2}$ is the equilibrium rate constant of the pseudosecond-order adsorption ( $\mathrm{g} / \mathrm{mg}$ - $\mathrm{min}$ ). It was observed from the kinetic study that the experimental data were fitted well with the second-order kinetics. Besides, the pseudosecond-order model fitted at different dye concentrations $(50,100$ and $150 \mathrm{mg} / \mathrm{L})$ is shown in Fig. 4. As shown in Fig. 4, the adsorption of acid fuchsin increases with increase in initial concentration and an adsorption capacity of $39.15 \mathrm{mg} / \mathrm{g}$ is found with an initial concentration of $50 \mathrm{mg} / \mathrm{L}$ after $120 \mathrm{~min}$. As the kinetic study was carried out

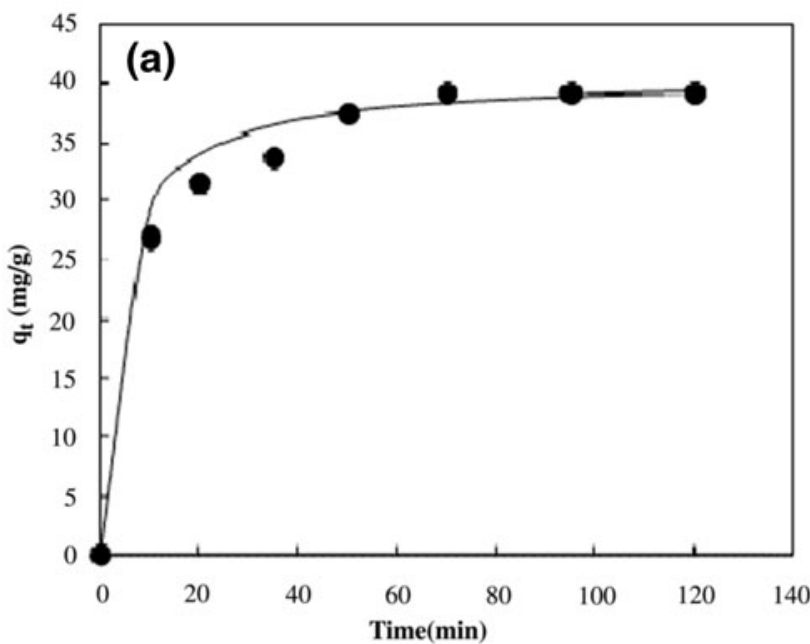

experimental data point

— pseudo second order model at varying initial dye concentrations $(50-150 \mathrm{mg} / \mathrm{L})$, three different values of the rate constant $\left(\mathrm{k}_{2}\right)$ were obtained, and they are noted in Table 1. It is observed that at the lower range of initial concentration, the $\mathrm{k}_{2}$-values increased, whereas at higher concentration the $\mathrm{k}_{2}$-values became almost constant. The values of good regression coefficient $\left(\mathrm{R}^{2}\right)$ were obtained for each concentration.

The adsorption isotherm

In order to investigate the equilibrium behavior, the experimental data were fitted to Freundlich, Langmuir and Temkin isotherms. The Langmuir isotherm represents the unimolecular adsorption of the adsorbate molecule on the adsorbent surface (Ozturk and Kavak 2005).

The Langmuir isotherm can be expressed as follows:

$q_{\mathrm{e}}=\frac{q_{\mathrm{m}} K_{\mathrm{L}} C_{\mathrm{e}}}{1+K_{\mathrm{L}} C_{\mathrm{e}}}$.

where $C_{\mathrm{e}}$ the equilibrium dye concentration, $q_{\mathrm{e}}$ is the equilibrium adsorption capacity, $K_{\mathrm{L}}$ is the Langmuir constant related to the energy of adsorption $(\mathrm{L} / \mathrm{mg})$, and $q_{\mathrm{m}}$ is the maximum amount of adsorption corresponding to complete monolayer coverage on the surface $(\mathrm{mg} / \mathrm{g})$. Similarly, the Freundlich isotherm can be used for non-ideal adsorption that involves heterogeneous surface energy systems (Ergene et al. 2009) and is expressed by the following equation:

$q_{\mathrm{e}}=K_{\mathrm{F}} C_{\mathrm{e}}^{\frac{1}{n}}$

where $K_{\mathrm{F}}$ is a rough indicator of the adsorption capacity, and $1 / n$ is the adsorption intensity. The Temkin isotherm describes the heat of adsorption and interaction between

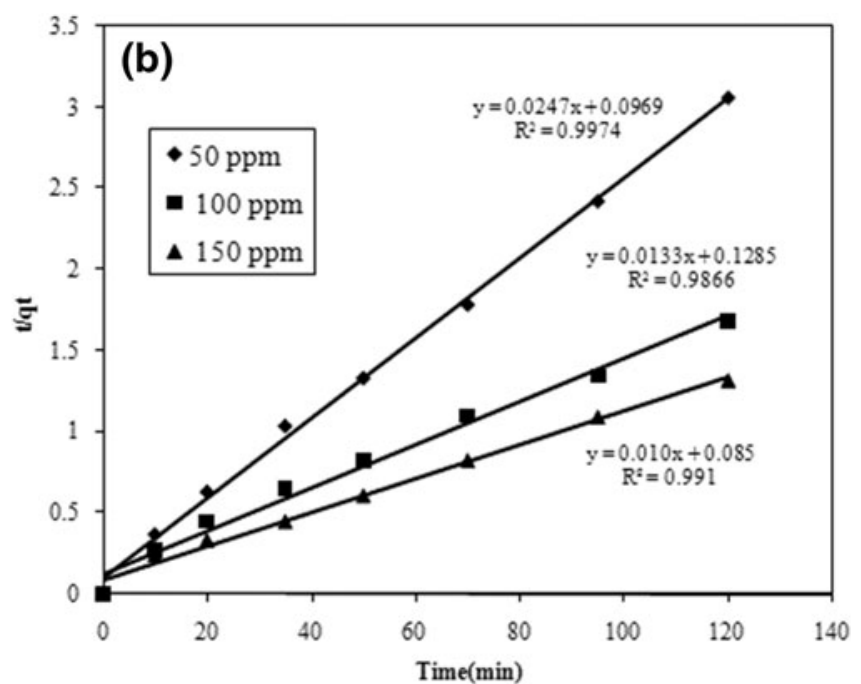

Fig. 4 a Pseudo-second-order model fitting at $50 \mathrm{mg} / \mathrm{L}$. b Pseudo-second-order model fit at various initial dye concentrations 
adsorbent and adsorbate molecules (Anbia et al. 2010), and it can be expressed as follows:

$q_{\mathrm{e}}=K_{\mathrm{m}} \log \left(h C_{\mathrm{e}}\right)$

The experimental data fitted with different adsorption isotherms are shown in Fig. 5. As shown in Fig. 5, the equilibrium behavior is well described by the Langmuir isotherm model. The values of parameters obtained for various adsorption isotherms are given in Table 2. As shown in Table 2, a high value of $R^{2}$ is obtained in case of Langmuir adsorption isotherm. The conformation of the experimental data into Langmuir isotherm model indicates the homogeneous nature of CAC surface.

\section{Column study}

The performance of the packed-bed column can be analyzed using breakthrough curves. The breakthrough curve mainly describes the adsorption characteristics of acid fuchsin in the fixed-bed column. The breakthrough curves were obtained by plotting the normalized concentration $\left(\mathrm{C}_{\mathrm{t}} / \mathrm{C}_{0}\right)$ (ratio of influent and effluent concentrations) versus

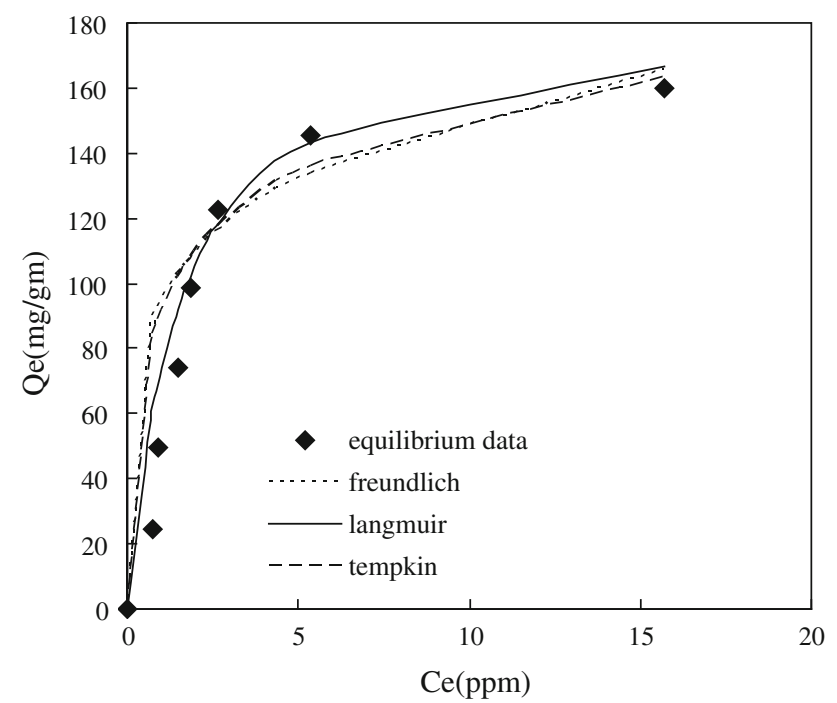

Fig. 5 Fitting of equilibrium models for fuchsin acid. Volume$100 \mathrm{~mL}, \mathrm{rpm}-2,000, \mathrm{pH}-6.01$, Temp-303 K)

Table 2 Equilibrium model parameters

\begin{tabular}{ll}
\hline Isotherm model & Kinetic parameters \\
\hline Freundlich & $K_{\mathrm{F}}=95.46885 ; n=4.99$ \\
$q_{\mathrm{e}}=K_{\mathrm{F}} C^{1 / n}$ & $K_{\mathrm{L}}=0.696 ; q_{\mathrm{m}}=181.82$ \\
Langmuir & \\
$q e=\frac{K_{1} q_{\mathrm{m}} C_{\mathrm{e}}}{1+K_{1} C_{\mathrm{e}}}$ & $K_{\mathrm{m}}=25.941 ; h=34.87436$ \\
Temkin & \\
$q_{\mathrm{e}}=K_{\mathrm{m}} \log \left(h C_{\mathrm{e}}\right)$ & \\
\hline
\end{tabular}

time or volume (Aksu and Gonen 2004). The total dye adsorbed $\mathrm{Q}_{0}(\mathrm{mg} / \mathrm{g})$ in the fixed-bed column was calculated using the following equation (Taty-Castodes et al. 2005):

$Q_{0}=\int_{0}^{V_{\mathrm{T}}} \frac{\left(C_{0}-C_{\mathrm{e}}\right) \mathrm{dV}}{m}$

where $m$ is the mass of the adsorbent $(\mathrm{g})$.

The value of $Q_{0}$ was affected by flowrate, initial dye concentrations and bed heights. Therefore, the effect of flowrate, bed height and initial concentration were studied subsequently.

\section{Effect of flowrate}

The effect of flowrate on the acid fuchsin adsorption was investigated by varying the flowrate of acid fuchsin from 5 to $15 \mathrm{~mL} / \mathrm{min}$, while the bed height and the initial feed concentration were held constant at $5.08 \mathrm{~cm}$ and $20 \mathrm{mg} / \mathrm{L}$, respectively. The breakthrough curve is shown in Fig. 6. The breakthrough time $\left(\mathrm{t}_{\mathrm{b}}\right)$ decreased from 20 to $2 \mathrm{~min}$ as the flowrate increased from 5 to $15 \mathrm{~mL} / \mathrm{min}$. In case of lower flowrate, the breakthrough occurred earlier as the fuchsin acid had more time to contact with the CAC bed, which resulted into lower fuchsin acid concentration in the effluent. The breakthrough curve became steeper with increasing flowrate, and this phenomenon may be well explained on the basis of mass transfer fundamentals (Ko et al. 2000). Increase in flowrate caused increase in rate of mass transfer and poor residence time, resulting in increasing outlet concentration and faster breakthrough. The similar result was also obtained when the removal of reactive black by granular activated carbon was studied in a fixed-bed column (Aksu et al. 2007). The standard deviations were calculated for the above case, and the corresponding deviation was found to be 0.000562 .

\section{Effect of initial feed concentration}

The effect of initial feed concentration on the breakthrough curve is shown in Fig. 7. As shown in Fig. 7, the breakthrough time decreased and the slope of the breakthrough curve increases with increasing feed concentration. This may occur due to lower concentration gradient at higher feed rate which further causes a small diffusion coefficient or mass transfer coefficient. Therefore, the diffusion process is concentration dependent. Besides, the dye loading rate increased with increasing feed rate resulted into a decreased adsorption zone length. The result obtained was in good agreement with the work done by Uddin et al. (2009). In case of effect of initial concentration, the standard deviation was found to be 0.000603 . 


\section{Effect of bed height}

To study the effect of bed height, the breakthrough experiments were performed at varying bed heights of 2.54, 5.08 and $7.62 \mathrm{~cm}$, while the feed concentration and the flowrate were held constant at $10 \mathrm{~mL} / \mathrm{min}$ and $20 \mathrm{mg} / \mathrm{L}$, respectively. The respective breakthrough curves are shown in Fig. 8.

The breakthrough time increases with increasing bed height. This happens because at higher bed height acid fuchsin remains in contact with the adsorbent for a longer duration, thus resulting in higher adsorptive capacity. As

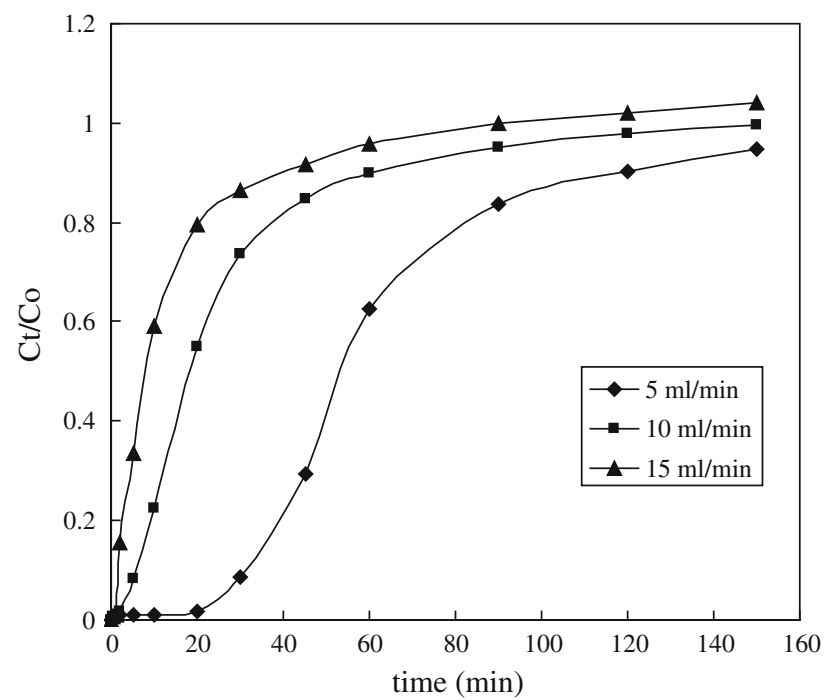

Fig. 6 Breakthrough curves for the removal of fuchsin acid by CAC pellet at different flowrate at constant bed height of $2.54 \mathrm{~cm}$ and feed concentration of $20 \mathrm{mg} / \mathrm{L}$

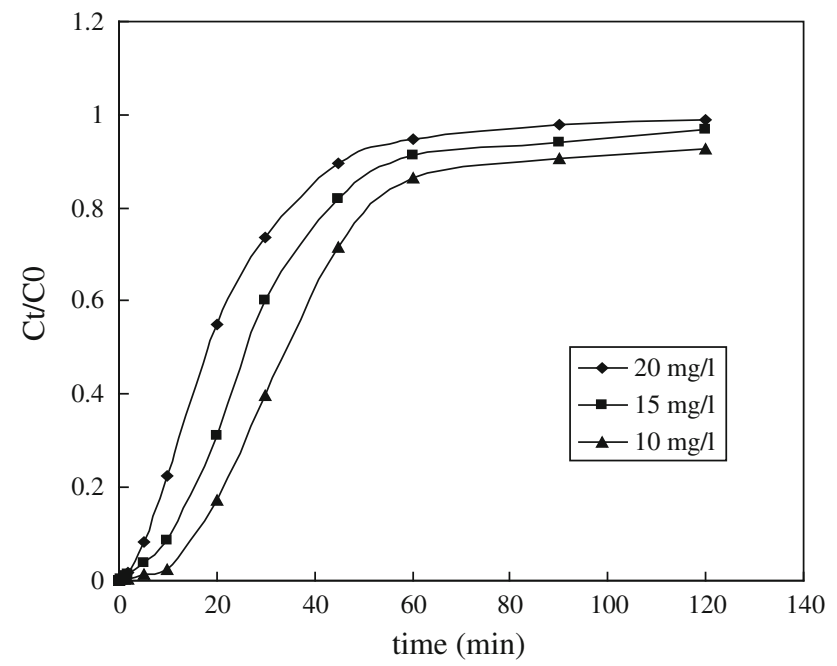

Fig. 7 Breakthrough curves for the removal of fuchsin acid by CAC at different initial fuchsin acid concentration at constant bed height of $2.54 \mathrm{~cm}$ and feed flowrate of $10 \mathrm{~mL} / \mathrm{min}$ the bed height increased, the amount of adsorbent was also increased, which provided more surface area and adsorptive sites for adsorption, resulting in decreased solute concentration in the effluent (Goel et al. 2005). The slope of the breakthrough curve was decreased with increasing highest bed height, which in turn increased the length of mass transfer zone. The maximum adsorption capacity was obtained at a bed height of $5.08 \mathrm{~cm}$ after which no appreciable change in effluent concentration was observed with further increase in bed height. The value of standard deviation was also calculated in case of effect of bed height, and it was found to be 0.0000004 .

The Bohart-Adams model

The Bohart-Adams model is widely used for designing fixed-bed column. The model is based on surface reaction theory (Kiran and Kaushik 2008), and according to this model, the rate of adsorption is proportional to fraction of adsorption capacity that still remains on the surface of the adsorbent (Lehmann et al. 2001). The Bohart and Adams model describes a fundamental relationship between the normalized concentration $\left(\mathrm{C}_{\mathrm{b}} / \mathrm{C}_{0}\right)$ and the bed height $(Z)$, and the relationship can be described by the following equation:

$t_{\mathrm{b}}=\frac{N_{0} Z}{C_{0} v}-\frac{1}{k_{\mathrm{AB}} C_{0}} \ln \left(\frac{C_{0}}{C_{\mathrm{b}}}-1\right)$

where $C_{0}$ and $C_{\mathrm{b}}$ are the initial and breakthrough concentrations in $\mathrm{mg} / \mathrm{L}$, respectively, $k_{\mathrm{AB}}$ is the BohartAdams model constant ( $\mathrm{L} / \mathrm{mg} \mathrm{min}), N_{0}$ is the adsorption capacity of the adsorbent in $\mathrm{mg} / \mathrm{L}, Z$ is the bed depth in $\mathrm{cm}$, $v$ is the linear velocity in $\mathrm{cm} / \mathrm{min}$, and $t_{\mathrm{b}}$ is the breakthrough time (min). The above equation can be written in a linear form as follows:

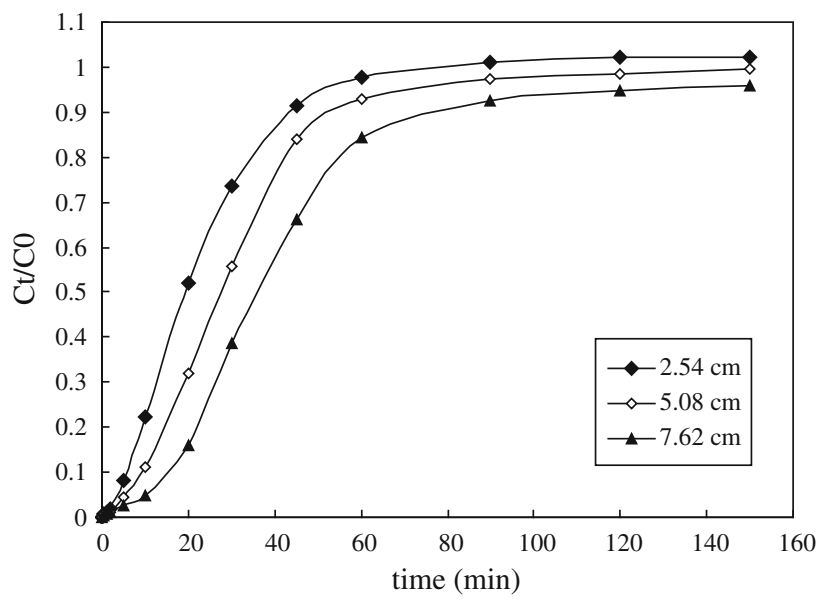

Fig. 8 Breakthrough curve for different bed height for fuchsin acid adsorption at constant flowrate and feed concentration of $10 \mathrm{~mL} / \mathrm{min}$ and $20 \mathrm{mg} / \mathrm{L}$ 


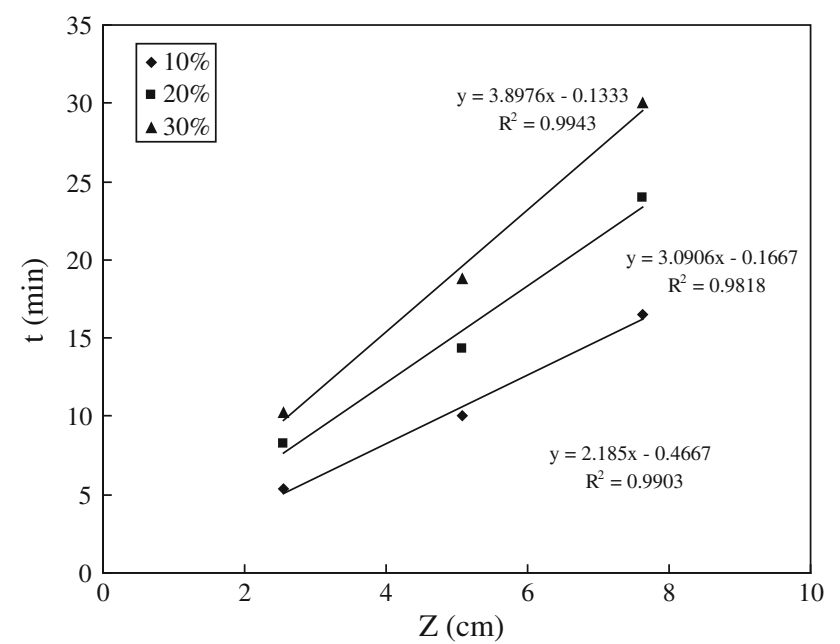

Fig. 9 Iso-removal lines for 10, 20 and $30 \%$ breakthrough for different bed heights at constant feed concentration of $20 \mathrm{mg} / \mathrm{L}$ and flowrate of $10 \mathrm{~mL} / \mathrm{min}$

$t_{\mathrm{b}}=a Z+b$

where

$a=\frac{N_{0}}{C_{0} v}$

$b=\ln \left[\left(\frac{C_{0}}{C_{\mathrm{b}}}\right)-1\right] \times \frac{1}{C_{0} k_{\mathrm{AB}}}$

The iso-removal lines are constructed by plotting different bed heights $(0.3,0.4$ and $0.5 \mathrm{~cm})$ against breakthrough times at constant flowrate $(10 \mathrm{~mL} / \mathrm{min})$ and initial dye concentration $(20 \mathrm{mg} / \mathrm{L})$ as shown in Fig. 9.

The adsorption capacity $\left(N_{0}\right)$ and the rate constant of adsorption $\left(k_{\mathrm{AB}}\right)$ were calculated from the slope and intercept of the isothermal lines. The values of $N_{0}$ and $k_{\mathrm{AB}}$ that can be further used in column design are shown in Table 3. Therefore, using the respective linear equation, the breakthrough time for a particular bed height for new feed concentration or flowrate can be predicted easily (Y.H. and Nelson 1984). The modified slope $\left(a_{\mathrm{f}}\right)$ for a new feed concentration was calculated directly by multiplying the original slope $\left(a_{\mathrm{i}}\right)$ by the ratio between the original and new feed concentration $\left(C_{\mathrm{f}}\right)$.

$a_{f}=a_{i}\left(\frac{C_{0}}{C_{f}}\right)$

The modified intercept was also calculated by the following equation:

$b_{f}=b_{i}\left(\frac{C_{0}}{C_{f}}\right)\left[\frac{\ln \left(C_{f}-1\right)}{\ln \left(C_{0}-1\right)}\right]$
Table 3 Bohart-Adams model constants for the fixed-bed column study

\begin{tabular}{llllll}
\hline $\begin{array}{l}\text { Iso-removal } \\
\text { Percentage }\end{array}$ & $\begin{array}{l}a_{\mathrm{i}} \\
(\mathrm{min} / \mathrm{cm})\end{array}$ & $\begin{array}{l}b_{\mathrm{i}} \\
(\mathrm{min})\end{array}$ & $\begin{array}{l}N_{0} \\
(\mathrm{mg} / \mathrm{L})\end{array}$ & $\begin{array}{l}k_{\mathrm{AB}} \\
(1 / \mathrm{min} \mathrm{mg})\end{array}$ & $R^{2}$ \\
\hline 10 & 2.185 & -0.4667 & 193.15 & 0.4708 & 0.9903 \\
20 & 3.09 & -0.1667 & 273.16 & 0.8278 & 0.9818 \\
30 & 3.89 & -0.1333 & 343.87 & 0.6356 & 0.9943 \\
\hline
\end{tabular}

where $b_{\mathrm{i}}$ and $b_{\mathrm{f}}$ are the original and modified intercept for a new feed concentration.

Similarly, the modified slope constant for a new flowrate was calculated as

$a_{\mathrm{f}}=a_{i}\left(\frac{V_{0}}{V_{\mathrm{f}}}\right)$

where $V_{0}$ and $V_{\mathrm{f}}$ are the original and new flowrate.

The predicted breakthrough time calculated from the above equations was compared with observed breakthrough time, and the corresponding values are shown in Tables 4 and 5. A high value of regression coefficient was obtained when these predicted values of breakthrough time were plotted against the observed values of breakthrough time. Therefore, model developed can be further utilized for modeling of a contentious column under different experimental conditions such as varying flowrates and feed concentrations.

\section{Yoon-Nelson model}

This model is based on the assumption that the rate of decrease in the probability of adsorption for each adsorbate molecule is proportional to the probability of adsorbate adsorption and the probability of adsorbate breakthrough on the adsorbent (Singh et al. 2009).

The Yoon-Nelson model is less complicated than other models. The linearized form of the Yoon-Nelson model for a single component system is expressed as:

$\ln \frac{C_{\mathrm{t}}}{C_{0}-C_{\mathrm{t}}}=k_{\mathrm{YN}} t-\tau k_{\mathrm{YN}}$.

where $k_{\mathrm{YN}}$ is the rate constant $\left(\mathrm{min}^{-1}\right)$, and $\tau(\min )$ is the time required for $50 \%$ adsorbate breakthrough. The values of $k_{\mathrm{YN}}$ and $\tau$ shown in Table 6 are determined from the slope and intercept of the linear plot of $\ln \left[C_{\mathrm{t}} /\left(C_{0}-C_{\mathrm{t}}\right)\right]$ and $\mathrm{t}$ according to Eq. (13). The $50 \%$ breakthrough time $(\tau)$ was increased with increasing feed concentration $\left(C_{0}\right)$ and decreasing bed height $(Z)$. Besides, the rate constant $\left(k_{\mathrm{YN}}\right)$ was increased with decreasing feed concentration and increasing bed height. The results obtained were in a good agreement with the experimental results of Ahmad and Hameed (2010). 
Table 4 Predicted breakthrough time form Bohart-Adams constant for a new feed concentration

\begin{tabular}{lllllllllll}
\hline $\begin{array}{l}\text { Break point } \\
(\%)\end{array}$ & $a_{\mathrm{i}}$ & $b_{\mathrm{i}}$ & $C_{\mathrm{i}}$ & $C_{\mathrm{f}}$ & $C_{\mathrm{i}} / C_{\mathrm{f}}$ & $a_{\mathrm{f}}$ & $b_{\mathrm{f}}$ & $Z$ & Predicted $\mathrm{t}_{\mathrm{b}}(\min )$ & Observed $\mathrm{t}_{\mathrm{b}}(\min )$ \\
\hline 10 & 2.185 & -0.467 & 20 & 10 & 2 & 4.37 & -0.69 & 2.54 & 10.40 & 15.5 \\
20 & 3.09 & -0.167 & 20 & 10 & 2 & 6.18 & -0.25 & 2.54 & 16 & 21 \\
30 & 3.89 & -0.133 & 20 & 10 & 2 & 7.78 & -0.19 & 2.54 & 20 & 24.5 \\
10 & 2.185 & -0.466 & 20 & 15 & 1.33 & 2.91 & -0.56 & 2.54 & 6.82 & 10 \\
20 & 3.09 & -0.167 & 20 & 15 & 1.33 & 4.10 & -0.19 & 2.54 & 10.21 & 15 \\
30 & 3.89 & -0.133 & 20 & 15 & 1.33 & 5.2 & -0.15 & 2.54 & 13.05 & 18 \\
\hline
\end{tabular}

Table 5 Predicted breakthrough time form Bohart-Adams constant for a new flowrate

\begin{tabular}{llllllllll}
\hline $\begin{array}{l}\text { Break point } \\
(\%)\end{array}$ & $a_{\mathrm{i}}$ & $b_{\mathrm{i}}$ & $V_{\mathrm{i}}$ & $V_{\mathrm{f}}$ & $V_{\mathrm{i}} / V_{\mathrm{f}}$ & $a_{\mathrm{f}}$ & $Z$ & Predicted $\mathrm{t}_{\mathrm{b}}(\min )$ & Observed $\mathrm{t}_{\mathrm{b}}(\mathrm{min})$ \\
\hline 10 & 2.185 & -0.467 & 10 & 15 & 0.66 & 1.44 & 2.54 & 3.6 & 2.5 \\
20 & 3.09 & -0.167 & 10 & 15 & 0.66 & 2.03 & 2.54 & 16 & 21 \\
30 & 3.89 & -0.133 & 10 & 5 & 2 & 7.78 & 2.54 & 20 & 24.5 \\
\hline
\end{tabular}

Table 6 Parameters for Yoon-Nelson under different experimental conditions

\begin{tabular}{llllll}
\hline $\begin{array}{l}\text { Initial } \\
\begin{array}{l}\text { concentration } \\
(\mathrm{mg} / \mathrm{L})\end{array}\end{array}$ & $\begin{array}{l}\text { Bed } \\
\text { height } \\
(\mathrm{cm})\end{array}$ & $\begin{array}{l}\text { Flowrate } \\
(\mathrm{mL} / \mathrm{min})\end{array}$ & $\begin{array}{l}k_{\mathrm{YN}}(1 / \\
\mathrm{min})\end{array}$ & $\begin{array}{l}\tau \\
(\mathrm{min})\end{array}$ & $R^{2}$ \\
\hline 20 & 2.54 & 10 & 0.0514 & 14.72 & 0.9594 \\
15 & 2.54 & 10 & 0.0386 & 16.67 & 0.9401 \\
10 & 2.54 & 10 & 0.0299 & 18.71 & 0.9413 \\
20 & 5.08 & 10 & 0.0460 & 19.88 & 0.9456 \\
20 & 7.62 & 10 & 0.034 & 24.11 & 0.9405 \\
\hline
\end{tabular}

Table 7 Clark model under different experimental conditions

\begin{tabular}{llllll}
\hline $\begin{array}{l}\text { Initial } \\
\text { concentration } \\
(\mathrm{mg} / \mathrm{L})\end{array}$ & $\begin{array}{l}\text { Bed } \\
\text { height } \\
(\mathrm{cm})\end{array}$ & $\begin{array}{l}\text { Flowrate } \\
(\mathrm{mL} / \mathrm{min})\end{array}$ & $\begin{array}{l}r(1 / \\
\mathrm{min})\end{array}$ & $A$ & $\mathrm{R}^{2}$ \\
\hline 20 & 2.54 & 10 & 0.0318 & 1.88 & 0.9853 \\
15 & 2.54 & 10 & 0.0174 & 1.25 & 0.9828 \\
10 & 2.54 & 10 & 0.0155 & 2.05 & 0.9827 \\
20 & 5.08 & 10 & 0.0386 & 4.48 & 0.9790 \\
20 & 7.62 & 10 & 0.0179 & 2.32 & 0.9020 \\
\hline
\end{tabular}

Clark model

The Clark model introduces a new procedure to simulate the breakthrough curves using the Freundlich isotherm constant (Batzias and Sidiras 2007). The linearized form of the model can be represented as

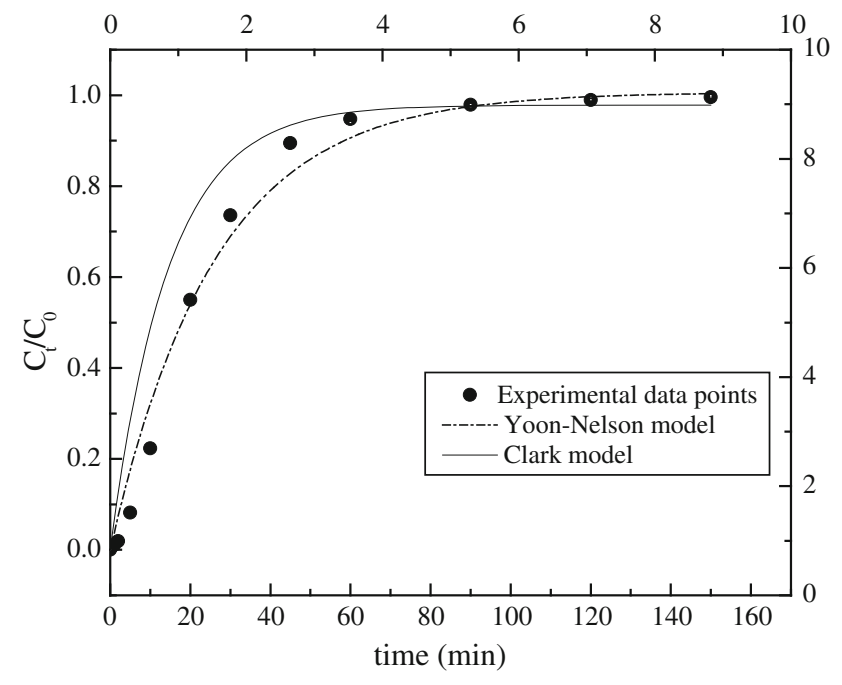

Fig. 10 Fitting of Yoon-Nelson model to the experimental breakthrough data

$\ln \left[\left(\frac{C_{0}}{C_{\mathrm{t}}}\right)^{n-1}-1\right]=-r t+\ln A$

where $r\left(\min ^{-1}\right)$ and $\mathrm{A}$ are the Clark model parameters.

The predicted model parameters calculated using a Freundlich constant of $n=4.99$ are shown in Table 7 .

As shown in Table 7, values of $r$ increased with increase in initial concentration and decrease in bed height. Besides, the value of A also increased with decrease in bed height. The Yoon-Nelson and Clark models were further fitted to the experimental breakthrough data (Fig. 10), and it can be seen that the behavior of the adsorption process can be well described using Yoon-Nelson model. 


\section{Conclusion}

The CAC pellets were prepared and successfully applied for the removal of acid fuchsin dye from its aqueous solution. It was observed that the prepared adsorbent had maximum adsorption capacity $(181.82 \mathrm{mg} / \mathrm{g})$ for fuchsin acid in batch adsorption study. The isotherm data fit well with the Langmuir adsorption isotherm. In the column study, the effects of different parameters such as bed height, initial concentration and flowrate were investigated, and it was found that the initial concentration and bed height had significant effect on the adsorption of fuchsin acid. The experimental breakthrough data were fitted to Bohart-Adams, Yoon-Nelson and Clark models, and it was found that the Yoon-Nelson model fitted well to the column data. It can be seen from Bohart-Adams model that with an increase in percentage breakthrough the values of $\mathrm{N}_{0}$ increased from $193.15-343.87 \mathrm{mg} / \mathrm{L}$, respectively.

Acknowledgments We are really thankful to all the technical staff members of the physical measurement laboratory of Indian Institute of Technology, Kharagpur, for their continuous help and support during the research work.

\section{References}

Adak A, Bandyopadhyay M, Pal A (2005) Removal of crystal violet dye from wastewater by surfactant-modified alumina. Sep Purif Technol 44(2):139-144

Afaq S, Rana KS (2009) Toxicological effects of leather dyes on total leukocyte count of fresh water teleost, Cirrhinus mrigala (Ham). Biol Medic 1(2):134-138

Ahmad AA, Hameed BH (2010) Fixed-bed adsorption of reactive azo dye onto granular activated carbon prepared from waste. J Hazard Mater 175(1-3):298-303

Aksu Z, Gonen F (2004) Biosorption of phenol by immobilized activated sludge in a continuous packed bed: prediction of breakthrough curves. Process Biochem 39(5):599-613

Aksu Z, Cagatey SS, Gonen F (2007) Continuous fixed bed biosorption of reactive dyes by dried Rhizopus arrhizus: determination of column capacity. J Hazard Mater 143(1-2):362-371

Amin NK (2009) Removal of direct blue-106 dye from aqueous solution using new activated carbons developed from pomegranate peel: adsorption equilibrium and kinetics. J Hazard Mater 165(1-3):52-62

Anbia M, Hariri SA, Ashrafizade SN (2010) Adsorptive removal of anionic dyes by modified nanoporous silica SBA-3. Appl Surf Sci 256(10):3228-3233

Attia AA, Rashwan WE, Khedr SA (2006) Capacity of activated carbon in the removal of acid dyes subsequent to its thermal treatment. Dyes Pigm 69(3):128-136

Baba M, Schols D, Pauwels R, Balzarini J, Clercq ED (1998) Fuchsin acid selectively inhibits human immunodeficiency virus (HIV) replication in vitro. Biochem Biophys Res Commun 155(3):1404-1411

Balint I, Miyazaki A (2009) Novel preparation method of well-defi mesostructured nanoaluminas via carbon-alumina composites. Micropor Mesopor Mater 122:216-222
Bastidas JM, Pinilla P, Cano E, Polo JL, Miguel S (2003) Copper corrosion inhibition by triphenylmethane derivatives in sulphuric acid media. Corros Sci 45(2):427-449

Batzias FA, Sidiras DK (2007) Dye adsorption by prehydrolysed beech sawdust in batch and fixed-bed systems. Bioresour Technol 98(6):1208-1217

Ergene A, Ada K, Tan Katırcığlu H (2009) Removal of Remazol Brilliant Blue $\mathrm{R}$ dye from aqueous solutions by adsorption onto immobilized Scenedesmus quadricauda: equilibrium and kinetic modeling studies. Desalination 249(3):1308-1314

Goel J, Kadirvelu K, Rajagopal C, Ggrg VK (2005) Removal of lead(II) by adsorption using treated granular activated carbon: batch and column studies. J Hazard Mater B125(1-3):211-220

Gupta V, Suhas k (2009) Application of low-cost adsorbents for dye removal-A review. J Environ Manage 90(8):2313-2342

Hashemian S (2010) $\mathrm{MnFe}_{2} \mathrm{O}_{4}$ /bentonite nano composite as a novel magnetic material for adsorption of acid red 138. African $\mathrm{J}$ Biotech 9(50):8667-8671

Hussein Md.Z, Yahaya AH, Shamsul Md.H, Salleh Md, Yap T, Kiu J (2004) Acid fuchsin-interleaved Mg-Al-layered double hydroxide for the formation of an organic-inorganic hybrid nanocomposite. Mater Letters 58(3-4):329-332

Kimberly A, Saliba TTE (1995) Mechanisms of the pyrolysis of phenolic resin in a carbon/phenolic composite. Carbon 33(11):509-1515

Kiran B, Kaushik A (2008) Cyanobacterial biosorption of $\mathrm{Cr}(\mathrm{VI})$ : application of two parameter and Bohart Adams models for batch and column studies. Chem Eng J 144(3):391-399

Ko DCK, Porter JF, Mckay G (2000) Optimised correlations for the fixed-bed adsorption of metal ions on bone char. Chem Eng Sci 55:5819-5929

Lehmann M, Zouboulis AI, Matis KA (2001) Modeling the sorption of metals from aqueous solutions on goethite fixed bed. Environ Pollut 113(2):121-128

Mahmoud Md E, Hafez OF, Osman MM, Yakout AA, Alrefaay A (2009) Hybrid inorganic/organic alumina adsorbents-functionalized-purpurogallin for removal and preconcentration of $\mathrm{Cr}(\mathrm{III})$, $\mathrm{Fe}(\mathrm{III}), \mathrm{Cu}(\mathrm{II}), \mathrm{Cd}(\mathrm{II})$ and $\mathrm{Pb}(\mathrm{II})$ from underground water. J Hazard Mater 176(1-3):906-912

Mahmoud ME, Osman MM, Hafez OF, Hegazi AH, Elmelegy E (2010) Removal and preconcentration of lead (II) and other heavy metals from water by alumina adsorbents developed by surface-adsorbed-dithizone. Desalination 251(1-3):123-130

Massoud MS, Mahmoud ME, Maximous NN (2004) Synthesis, characterization, and selective metal binding properties of physically adsorbed 2-thiouracile on the surface of porous silica and alumina. Mikrocim Acta 147(1-2):111-115

Oguza E, Keskinler B (2005) Determination of adsorption capacity and thermodynamic parameters of the PAC used for bomaplex red CR-L dye removal. Coll Surf A Physicochem Eng Asp 268(1-3):124-130

Ozturk N, Kavak D (2005) Adsorption of boron from aqueous solutions using fly ash: batch and column studies. J Hazard Mater 127(1-3):81-88

Singh S, Srivastava VC, Mall ID (2009) Fixed-bed study for adsorptive removal of furfural by activated carbon. Coll Surf A Physicochem Eng Asp 332(1):50-56

Song J, Zou W, Bian Y, Su F, Han R (2010) Adsorption characteristics of methylene blue by peanut husk in batch and column modes. Desalination 265(1-3):119-125

Taty-Castodes VC, Fauduet H, Porte C, Ho YS (2005) Removal of lead(II) ions from synthetic and real effluents using immobilized Pinus sylvestris sawdust: adsorption on a fixed column. J Hazard Mater B 123(1-3):135-144

Uddin MdT, Rukanuzzaman MD, Khan MR, Islam MdA (2009) Adsorption of methylene blue from aqueous solution by jackfruit 
(Artocarpus heteropyllus) leaf powder: a fixed-bed column study. J Environ Manage 90(11):3443-3450

Verma Y (2008) Toxicity evaluation of effluents from dye and dye intermediate producing industries using daphnia bioassay. Internet J Toxic 4(2):1559-3916

Yang N, Zhu S, Zhang D, Xu S (2008) Synthesis and properties of magnetic $\mathrm{Fe}_{3} \mathrm{O}_{4}$-activated carbon nanocomposite particles for dye removal. Mater Letters 62(4-5):645-647
Yoon YH, Nelson JH (1984) Application of gas adsorption kinetics I. a theoretical method for respirator cartridge service time. Am Ind Hyg Assoc 45(8):517-524

Zhang G, Qu J, Liu H, Cooper AT, Wu R (2007) $\mathrm{CuFe}_{2} \mathrm{O}_{4}$ /activated carbon composite: a novel magnetic adsorbent for the removal of acid orange II and catalytic regeneration. Chemosphere 68(6):1058-1066

Zhu HY, Jiang R, Xiao L (2010) Adsorption of an anionic azo dye by chitosan/kaolin/ $\gamma$-e2O3 composites. Appl Clay Sci 48(3):522-526 